\title{
Navigating the water trilemma: a strategic assessment of long-term national water resource management options for Great Britain
}

\author{
Ives, M.C. ${ }^{1}$, Simpson, M. ${ }^{1,2}$, Hall, J.W. ${ }^{1}$ \\ 1. University of Oxford, Environmental Change Institute 2. Centre for Ecology \& Hydrology
}

\begin{abstract}
Potential increases in water demand, alongside uncertainties in water availability due to climate change, mean that Britain's water supply system could become increasingly stressed over the coming decades. Along with the need for secure water supplies, we must ensure that the supply is affordable and that sufficient water is available to safeguard the natural environment. Meeting these three separate goals of security, affordability and sustainability, with their inevitable trade-offs, can be termed the "water trilemma". In this novel approach we simulate projections of river flows under population and climate change by using an aggregated national water resource model to test potential policies to manage demand and investments in water supply infrastructure in order to assess Britain's ability to meet its needs into the future. The results indicate that a balanced approach which allows for some interbasin water transfers while also engaging local solutions, including water re-use, combined with scalable actions for demand management and leakage reduction, will best enable Britain to navigate this water trilemma.
\end{abstract}

\section{Introduction}

Since the privatisation of the water industry in England and Wales in 1989, water resources planning has been conducted by separate water companies, the Environment Agency, the Scottish Environment Protection Agency and Natural Resources Wales. Whilst there are some significant inter-company water transfers, there has not been a demonstrable need for a more strategic national view of water resources. That situation is now changing. There is a growing recognition of the need to establish a strategic national perspective on the resilience of Britain's water supply systems and the need for options that preserve and enhance resilience (Water UK, 2016). The possibility of major inter-company transfers, accompanied by new storage infrastructure, heightens the need to establish a strategic overview of the risks of water shortage and the options for managing those risks.

Looking to the future, there are upward drivers on water demand, in particular population growth, which is expected to be concentrated in the south-east of England. Over-abstraction from water bodies, along with other environmental stressors, means that many of Britain's rivers and lakes are not in a good ecological status. Consequently, there is an emphasis on programmes to restore sustainable abstractions and reform abstraction regulations (POST, 2017).

The effects of climate change on water availability are more uncertain. Patterns of future precipitation are very difficult to predict, although projected temperature increases will likely intensify evapotranspiration and hence reduce water availability (Prudhomme et al., 2013, Arnell, 2004, Hannaford and Buys, 2012). The latest UK Climate Change Risk Assessment anticipates a decline of $10 \%$ to $30 \%$ in deployable output of water by 2050 under a medium emissions scenario (Defra, 2012). The most recent climate projections for the UK are the UKCP09 scenarios (Jenkins et al., 2009). Prudhomme et al. (2013) employed regional climate model outputs from UKCP09 to generate a Future Flows Hydrology dataset, which 
comprises of 11 scenarios for river time series from 1951 to 2098 for 282 sites across the UK. More recently, this dataset was extended to provide for 'Low emissions' and 'High emissions' scenarios (HR Wallingford, 2015), resulting in a total of 33 possible climate scenarios. Applying such hydrological projections has become an accepted methodology for climate change impact assessments conducted by water companies (Environment Agency et al., 2012). As with earlier projections of climate change, the anticipated spread of future hydrological conditions projected by the Future Flows scenarios is broad (Prudhomme et al., 2013) and attaching probability to each scenario is not straightforward (Rougier, 2007, Brown and Wilby, 2012).

With growing pressure on water supplies, the need for strategic national planning or new national policies cannot be overlooked, and therefore it is becoming increasingly necessary to adopt a national perspective on the assessment of water resource systems. In this paper we propose a pragmatic approach to national water resources assessment and apply this methodology to test a wide range of possible investments and policies to secure the resilience of Britain's water supplies.

\section{Methodology}

We have developed a high level national water resources model that accounts for water use and the reliability of water supplies at the scale of Water Resource Zones (WRZ). The model was built bespoke as part of the ITRC National Infrastructure Systems Model (NISMOD) (Hall et al., 2016) using a combination of technologies, including Matlab for the hydrological yield modelling, and Microsoft VB.Net for the long-term water supply and infrastructure modelling. The model uses an aggregate estimate of surface and groundwater availability in each WRZ (as described below) and simulates the effect of storage, transfer, re-use and desalination supply infrastructure, as well as changes in water use and leakage.

\section{Water demand}

Water resources planning in Britain is conventionally based around Water Resource Zones, which are areas where water users may be considered to be supplied by the same system and subject to the same supply risks (Figure 1).

Current per capita water consumption levels were identified for each water company across the study area based on the Water Resources Management Plan (WRMP). Non-domestic demands for water were identified from reported Environment Agency figures for six English regions plus Wales (Environment Agency, 2012). Largely non-consumptive users of water were discounted from these demand datasets. Leakage figures were also identified from WRMPs for each water company. Domestic demand was modelled as population multiplied by each company's reported per capita consumption figures. Three scenarios were used to model future population, i.e. a low, central and high population. Total demand was calculated as the sum of domestic demand (deployable output), non-domestic demand and leakage. 


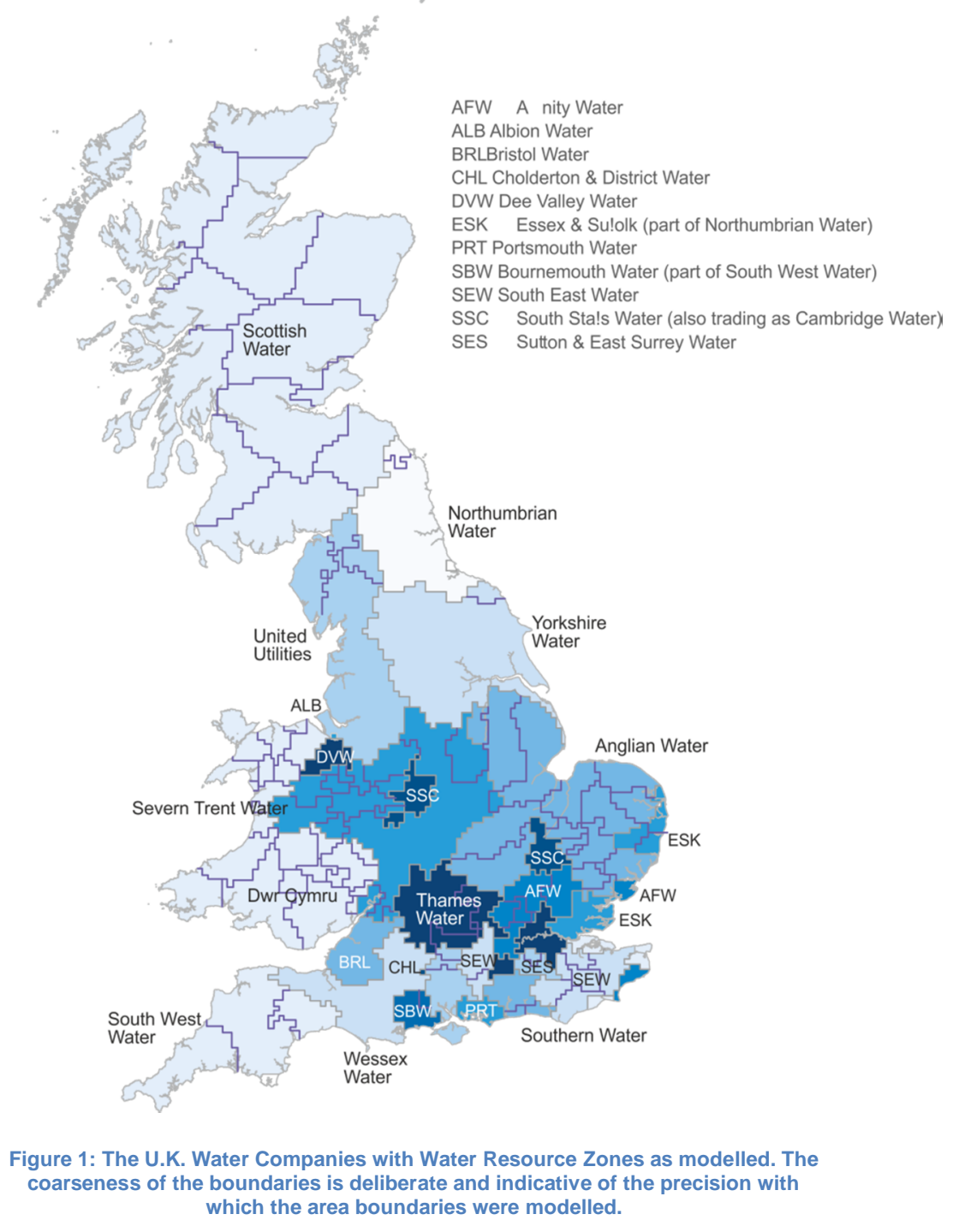

\section{Water supply}

For each WRZ that utilises a river or reservoir source, a representative river gauge was identified from the National River Flow Archive (http://www.ceh.ac.uk/data/nrfa/). For WRZ with multiple river abstraction points, a composite representative river abstraction area was created by summing the total unique abstraction sub-catchment areas. The ratio of this area to the gauged sub-catchment was used to scale the observed series. (see the Supplementary Material for more detail). These time series of river intakes were then restricted based on their documented minimum river flows and licenced abstraction volumes. Some extremely small zones, entirely reliant on water imports, were merged with the zones upon which they depend. In Scotland, mega-zones were used in place of WRZs (Figure 1).

To incorporate the uncertainty represented by climate change, a total of 33 climate scenarios were developed. Time series of water supply were generated for each of the WRZ from the original 11 UKCP09 medium emissions scenarios generated for the Future Flows Hydrology data series (Prudhomme et al., 2012). An additional 11 low and 11 high emission scenarios were generated for the UK's 2nd Climate Change Risk Assessment (HR Wallingford, 2015), producing a wide range of possible climate scenarios (Ives and Simpson, 2017).

For simplicity, the climate and socio-economic scenarios were reduced to three combinations: (i) a "High and Dry" scenario, consisting of highest population growth and the 
lowest total national future river flows in the 'High emissions' scenarios; (ii) a "Central" scenario, consisting of central population growth and a scenario of central total future river flows in the 'Medium emissions' scenarios; and (ii) a "Low and Wet" scenario, consisting of the lowest population growth and the highest total national future river flows in the 'Low emissions' scenarios.

Representative reservoir volumes for each WRZ were identified using the total reservoir capacity for the WRZ. Reservoir storage time series were modelled using a simple water balance of inflow and withdrawals. Direct supply from groundwater was obtained using existing Deployable Outputs reported for groundwater sources, whilst direct abstractions from rivers were based on licensed abstraction volumes and minimum river flows. For more information on the workings of the Supply Module, see the Supplementary Material. Initial estimates used in the modelling for 2015 per capita consumption, deployable output and total distribution leakage for each company are also provided in the Supplementary Material (Table A2).

Several catchments in Britain are deemed to have unsustainable rates of water withdrawal, which is threatening the ecological status of the catchment as defined under the EU Water Framework Directive. Reductions in licenced withdrawals are therefore proposed by the Environment Agency to restore environmental flows as part of their Restoring Sustainable Abstractions programme (See Table A4 in the Supplementary Material for the list of revised abstraction arrangements by company). These amount to a total reduction in water supply of 196,800 Ml/year and replicate those used in Water UK's "base" scenario (Water UK, 2016).

The reliability of the water resource system is analysed using the expected frequency with which restrictions on water use are triggered (Hall et al., 2012, Borgomeo et al., 2014). For this purpose we use an annual time-based reliability index (McMahon et al., 2006), which is calculated as the number of times Level 1 restrictions on water use are required by any company, divided by the number of years in the modelling period (2015 to 2040). During shortages, per capita consumption is assumed to be reduced by a percentage based on estimates in WRMPs, which allows for an estimation of deployable output that can be abstracted without incurring a breach of level of service restrictions (DO in Table A1). In practice, water companies have greater concern for more severe restrictions, but focussing upon Level 1 restrictions (which, by definition, are more frequent) enables a more sensitive and stable estimate of reliability.

\section{Simulating adaptive strategies}

A model run involves a national water resource management strategy, combined with a future scenario of socio-economic demand, and one of the 33 future flow series for the years 2015 to 2040 . The model simulates a planning process that looks ahead over a 25-year planning horizon in order to decide what interventions would be necessary on the supply and/or demand side. That planning process is revisited every 5 years during a simulation where a supply/demand balance is calculated for each water resource zone on an annual basis, out to the planning horizon. If any of these years does not show a positive supply balance, a decision to address the supply-demand imbalance is made. For this, the model identifies the additional supply required to balance demand.

Financial and carbon costs are determined for the additional water required over the length of the planning horizon. An optimal planning decision algorithm then minimises the Total Present Value Costs (TotPVC) per unit of water supplied for each investment across the suite of available investment options for each water company (see Supplementary Material for details on these calculations). Once the minimum cost investment is found, the 
intervention is implemented immediately and the additional yield generated is added to supply within the company from the next year onwards.

\section{Water supply options and strategies}

The Water Resource Planning Guideline (EA et al., 2012) identifies 43 generic options for enhancing water availability by either increasing available supply or by reducing demand. Here we used a reduced list of eight types of investment and policy options, specifically reservoir expansion (RE), aquifer storage and recovery (AR), new surface water sources $(S W)$, new groundwater sources (GW), transfers (TR), effluent re-use (ER), demand reduction (DR) and leakage reduction (LR). A database of 864 costed options from WRMPs was created, with each option associated with one of the eight alternative types. Each investment option had an identified cost in terms of capital expenditure and operational expenditure, and in associated carbon cost, as a function of energy use (Tooms et al., 2011, Lemos et al., 2013). These alternative investment types represent both supply and water saving options. Further details on the calculation of costs for water supply options are provided in the Supplementary Material.

A number of variants on the least cost planning strategy were developed to test alternative options for the provision of water on a national scale. Each strategy represents a different approach to policy intervention, choices of technologies used to increase supply or decrease demand, and policies around promoting inter-company transfers. The exact investments are not pre-specified, but are triggered by rules within the strategy regarding the options available, modified by subsidies that promote the uptake of particular options (e.g. demand reduction), or constraints on infrastructure types in certain areas (e.g. desalination is only an option for coastal/estuarial WRZ's).

The main alternative management strategies are summarized as follows:

- No Build (NB): a baseline strategy involving no new investment or policies in any future year. This strategy was used to validate model outputs and to estimate the impacts of population growth and climate change in the absence of any plans to address supply-demand deficits.

- Minimal Intervention (MI): a low investment strategy that utilises modest use of leakage reduction, reservoir enhancements, aquifer recharge and new groundwater resources. There is no further investment in inter-company transfers, limited deployment of desalination, no water re-use and little action to manage demand

- Capital Expenditure (CE): a strategy that focuses on building large scale, long-term investments in supply infrastructure to meet increasing demand, involving no demand reduction, medium leakage reduction and no water re-use. Supply-side investments include reservoir enhancement, new groundwater resources, desalination plants and any inter-company transfers allowed between adjacent water companies.

- National Planning (NP): exactly the same as the CE strategy with the added adaptation that in scenarios where shortages are projected, and no local options are available for water supply enhancement, extra capacity is built in neighbouring water companies and water is transferred to the company in need.

- System Efficiency (SE): a strategy that focuses on increased efficiency of water use and targeting measures to reduce the need for additional infrastructure. This strategy embraces ambitious demand reduction and leakage reduction while investing in desalination plants, water re-use, or inter-basin transfers when these are the most cost-effective alternatives. 
- System Restructuring (SR): focusing on rethinking the infrastructure system through innovation with a combination of new local delivery options and efficiency schemes. This strategy involves medium demand action, high leakage reduction, inter-company transfers and the promotion of water re-use.

Finally, four key performance indicators were used to assess each of these alternative national water management strategies using multi-criteria decision analysis. The indicators used were based on the examination of the water trilemma around security (reliability), affordability, and sustainability, and were as follows:

- Reliability: indicates the ratio of years in which restrictions on water use required over the period from 2015 to 2040 (see above).

- Total Cumulative Costs: The discounted present value costs in 2015 pounds (£) of constructing any new water supply infrastructure and maintaining existing and new infrastructure between 2015 and 2040. Capex and Opex are also reported separately as secondary performance indicators.

- Total Water Supplied: provides the total amount of water extracted from the environment and supplied to the system (ML) in 2040. Environmental impact is minimised by reducing this indicator where possible. The total amount of water lost through distribution leakage (ML) in 2040 is also reported as a secondary performance indicator.

- Cumulative $\mathrm{CO}_{2} \mathrm{e}$ emissions: an estimate of the cumulative amount of $\mathrm{CO}_{2}$ equivalent greenhouse gases emitted from operating any water supply infrastructure. This indicator does not include any embodied carbon emissions from the production of any materials used or from the construction of assets.

\section{Decision analysis}

We implement a multi-criteria decision analysis (MCDA) approach to explore the effectiveness of each strategy in ensuring secure, reliable and environmentally sustainable water supplies, against the background of uncertainties associated with socio-economic, climatic and institutional change.

A number of alternatives exist for assessing and visualising trade-offs involving multiple criteria in water management (Jenkins et al., 2004, Kasprzyk et al., 2009, Beck and Villarroel Walker, 2013, Zeff et al., 2014, Giuliani et al., 2014, Hurford et al., 2014, Poff et al., 2015, Herman, 2015). In this study we make use of the ELECTRE ${ }^{1}$ III approach (Roy, 1978), which uses outranking relations that systematically compare the alternatives with respect to each criterion (Hassan, 2013, Zavadskas and Turskis, 2011).

Three alternative preference sets were developed that reflect alternative perspectives in respect to the water trilemma. Table 1 shows the weighting associated with each preference set. In all cases low values of each indicator are preferred to higher values; e.g. low cost and low emissions are preferred. The "No preference" set (NoPref) weighs each of the three components of the trilemma, namely reliability, affordability and sustainability, equally. The "Security and Cost" set focuses on reliability at the least cost, and the "Green is Good" strategy focuses on limiting carbon emissions and lowering abstractions from the environment. These weighting are then used as part of the MCDA algorithm to rank how each strategy performs across the various scenarios of future uncertainty.

\footnotetext{
${ }^{1}$ ELECTRE stands for Elimination Et Choix Traduisant la Realité (Elimination and Choice Translating Reality)
} 
Table 1: Weightings associated with each of the alternative preference sets including "Security \& Cost", "No Preference", and "Green is Good".

\begin{tabular}{|l|c|c|c|}
\hline & Security \& Cost & No Preference & Green is Good \\
\hline Reliability & $70 \%$ & $33 \%$ & $15 \%$ \\
\hline Total Cost & $20 \%$ & $33 \%$ & $5 \%$ \\
\hline Water Supplied & $50 \%$ & $17 \%$ & $30 \%$ \\
\hline CO2e emissions & $50 \%$ & $17 \%$ & $50 \%$ \\
\hline
\end{tabular}

A sensitivity analysis around indifference, preference and veto thresholds used in the ELECTRE III method (Almeida Dias et al., 2006) was performed using the outrankingTools package in R-project (R Core Team, 2013). The sensitivity analysis involved calculating the average ELECTRE ranking across the range of preference sets and scenarios with $50 \%$ increases and decreases in each of the threshold parameters. The base threshold values used are shown in Table A5 of the Supplementary Material.

\section{Results}

The impact of the three scenarios and five alternative water management strategies on the supply/demand balance in 2040 are presented in Figure 2. Population growth (blue bar) and sustainability reductions (red bar) increase the demand for water supplies, which are impacted either positively or negatively by progress in terms of demand management (green bar) or leakage management (purple bar). The System Efficiency (SE) and System Restructure (SR) strategies are the only two that have demand management and leakage reduction that actually reduce total water use in the face of population growth.

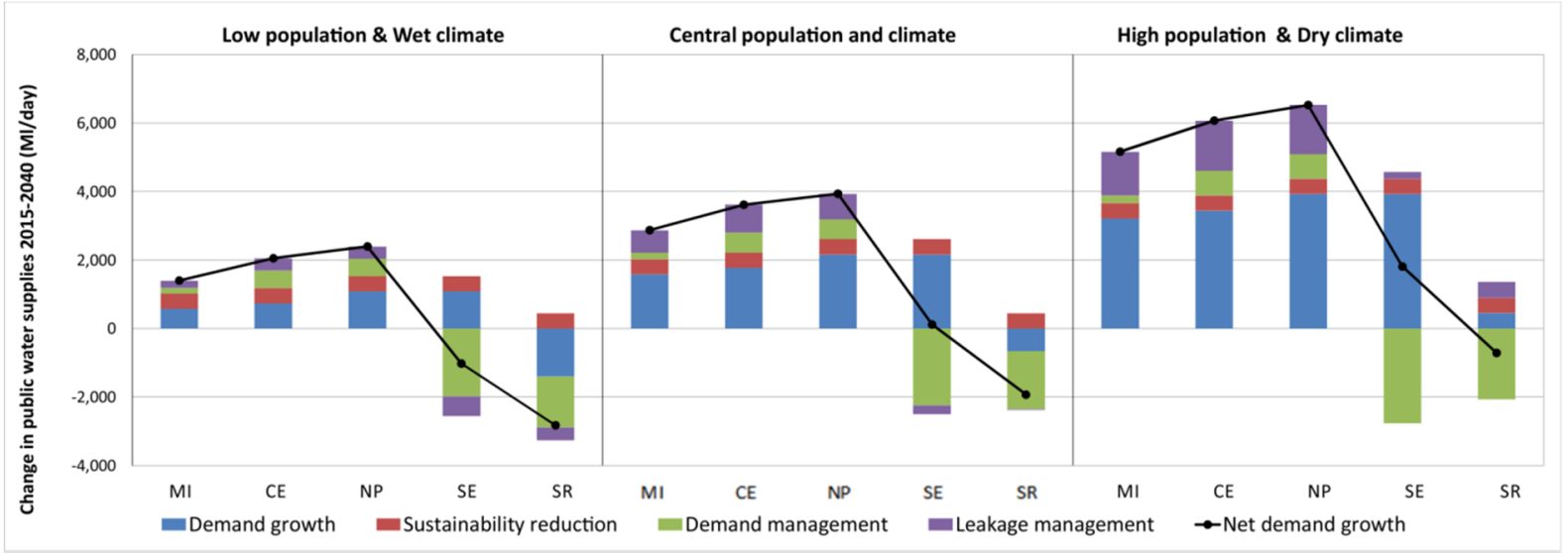

Figure 2: Projections of changing use of public water supply and the effect of the various management strategies on demand and leakage reductions under low, central and high population growth.

More results from the modelling are presented in Table 2 for each of the six possible strategies under the three alternative scenarios. The No Build (NB) strategy is presented for comparison with other investment strategies and for verification purposes. As expected in the NB strategy water supplied, $\mathrm{CO}_{2} \mathrm{e}$ emissions and the reliability measure increase for the scenarios with higher population growth rates and drier climates. 
Table 2: Model outputs from the six strategies under three alternative scenarios for the following national-level performance indicators (a) water supplied to customers in 2040 (thousands of MI/day), (b) total number of years that companies cannot meet their level of service (LOS) agreements between 2015 and 2040, (c) Discounted cumulative costs in Opex and new Capex from 2015 to 2030 ( $(\mathrm{bn})$, and (d) Cumulative CO2 equivalent emissions in 2040 (Mt), (e) Total leakage in 2040 (thousands of MI/day), (f) discounted cumulative Capex costs ( $(\mathrm{bn})$ and $(\mathrm{g})$ discounted cumulative Opex from 2015 to 2040 ( $(\mathrm{bnn}$ ). The three scenarios are Low \& Wet - low population growth and wetter climate, Central - central population growth and water flow levels, High and Dry high population growth coupled with drier climatic conditions.

\begin{tabular}{|l|c|c|c|}
\hline (a) 2040 Water Supplied ('000 MI/day) & \multicolumn{3}{|c|}{ Scenario } \\
\hline Strategy & Low \& Wet & Central & High \& Dry \\
\hline No Build (NB) & 18.0 & 17.7 & 17.3 \\
\hline Minimum Intervention (MI) & 18.5 & 19.8 & 20.3 \\
\hline Capacity Expansion (CE) & 19.1 & 20.3 & 20.7 \\
\hline National Planning (NP) & 19.5 & 21.0 & 22.9 \\
\hline System Efficiency (SE) & 15.3 & 16.3 & 17.2 \\
\hline System Restructure (SR) & 16.1 & 17.2 & 19.6 \\
\hline
\end{tabular}

\begin{tabular}{|l|c|c|c|}
\hline (b) 2015-2040 Reliability & \multicolumn{3}{|c|}{ Scenario } \\
\hline Strategy & Low \& Wet & Central & High \& Dry \\
\hline No Build (NB) & 0.32 & 0.53 & 0.70 \\
\hline Minimum Intervention (MI) & 0.26 & 0.25 & 0.40 \\
\hline Capacity Expansion (CE) & 0.13 & 0.25 & 0.41 \\
\hline National Planning (NP) & - & - & - \\
\hline System Efficiency (SE) & 0.01 & 0.10 & 0.27 \\
\hline System Restructure (SR) & - & - & - \\
\hline
\end{tabular}

\begin{tabular}{|l|c|c|c|}
\hline (c) 2015-2040 Cumulative Cost (£bn) & \multicolumn{3}{|c|}{ Scenario } \\
\hline Strategy & Low \& Wet & Central & High \& Dry \\
\hline No Build (NB) & 8.5 & 8.5 & 8.5 \\
\hline Minimum Intervention (MI) & 9.0 & 10.1 & 10.8 \\
\hline Capacity Expansion (CE) & 11.9 & 12.5 & 12.9 \\
\hline National Planning (NP) & 26.0 & 48.1 & 77.3 \\
\hline System Efficiency (SE) & 21.9 & 22.2 & 24.4 \\
\hline System Restructure (SR) & 20.0 & 26.2 & 47.2 \\
\hline
\end{tabular}

\begin{tabular}{|l|c|c|c|}
\hline (d) 2015-2040 Cum. $\mathbf{C O}_{2} \mathrm{e}$ Emissions (Mt) & \multicolumn{3}{|c|}{ Scenario } \\
\hline Strategy & Low \& Wet & Central & High \& Dry \\
\hline No Build (NB) & 40.0 & 38.2 & 36.6 \\
\hline Minimum Intervention (MI) & 43.7 & 49.2 & 48.7 \\
\hline Capacity Expansion (CE) & 44.1 & 48.5 & 49.5 \\
\hline National Planning (NP) & 52.8 & 64.7 & 67.7 \\
\hline System Efficiency (SE) & 42.4 & 41.2 & 43.7 \\
\hline System Restructure (SR) & 42.4 & 48.1 & 65.0 \\
\hline
\end{tabular}

\begin{tabular}{|l|c|c|c|}
\hline (e) 2040 Total Leakage ('000 Ml/day) & \multicolumn{3}{|c|}{ Scenario } \\
\hline Strategy & Low \& Wet & Central & High \& Dry \\
\hline No Build (NB) & 2.0 & 2.2 & 2.5 \\
\hline Minimum Intervention (MI) & 2.0 & 2.2 & 2.5 \\
\hline Capacity Expansion (CE) & 2.1 & 2.3 & 2.6 \\
\hline National Planning (NP) & 2.1 & 2.3 & 2.6 \\
\hline System Efficiency (SE) & 1.6 & 1.7 & 1.9 \\
\hline System Restructure (SR) & 1.6 & 1.8 & 2.0 \\
\hline
\end{tabular}

(f) 2015-2040 Cumulative Capex (Ebn)

Scenario

\begin{tabular}{|l|c|c|c|}
\hline Strategy & Low \& Wet & Central & High \& Dry \\
\hline No Build (NB) & 0.0 & 0.0 & 0.0 \\
\hline
\end{tabular}




\begin{tabular}{|l|c|c|c|}
\hline Minimum Intervention (MI) & 0.1 & 1.0 & 1.2 \\
\hline Capacity Expansion (CE) & 0.3 & 1.1 & 1.2 \\
\hline National Planning (NP) & 6.7 & 23.1 & 25.5 \\
\hline System Efficiency (SE) & 0.1 & 0.1 & 0.3 \\
\hline System Restructure (SR) & 0.0 & 0.3 & 6.4 \\
\hline
\end{tabular}

\begin{tabular}{|l|c|c|c|}
\hline \multirow{2}{*}{ (g) 2015-2040 Cumulative Opex (£bn) } & \multicolumn{3}{|c|}{ Scenario } \\
\hline Strategy & Low \& Wet & Central & High \& Dry \\
\hline No Build (NB) & 8.5 & 8.5 & 8.5 \\
\hline Minimum Intervention (MI) & 8.9 & 9.1 & 9.6 \\
\hline Capacity Expansion (CE) & 11.6 & 11.4 & 11.7 \\
\hline National Planning (NP) & 19.4 & 25.1 & 51.8 \\
\hline System Efficiency (SE) & 21.7 & 22.1 & 24.2 \\
\hline System Restructure (SR) & 20.0 & 25.9 & 40.8 \\
\hline
\end{tabular}

The water balance for each company in 2040 under the NB strategy is presented geographically Figure 3. Most WRZs experience water shortages in the 'high and dry' scenario, as do many in the 'central' scenario, if only current (2015) infrastructure assets are available in 2040. These results are consistent with the analyses of HR Wallingford (2015) and Water UK (2016), although a full comparison with their results is not possible because of differences in modelling approaches and drought scenarios. Note that the Water UK analysis used Water Available for Use (WAFU) rather than Deployable Outputs (DO). Reporting WAFU results in significantly lower supply volumes as WAFU accounts for outages from maintenance, losses in water processing, and target headroom. Each of these studies used similar population scenarios and sustainability reductions, but HR Wallingford assumed higher leakage reduction rates and the Water UK study assumed higher per capita consumption reductions than the most ambitious strategy presented here (System Efficiency). They also utilized more extreme drought scenarios such that even with the use of 'Low emissions' and 'High emissions' scenarios the range of water balances presented here are not as extreme as those presented in the Water UK report. 


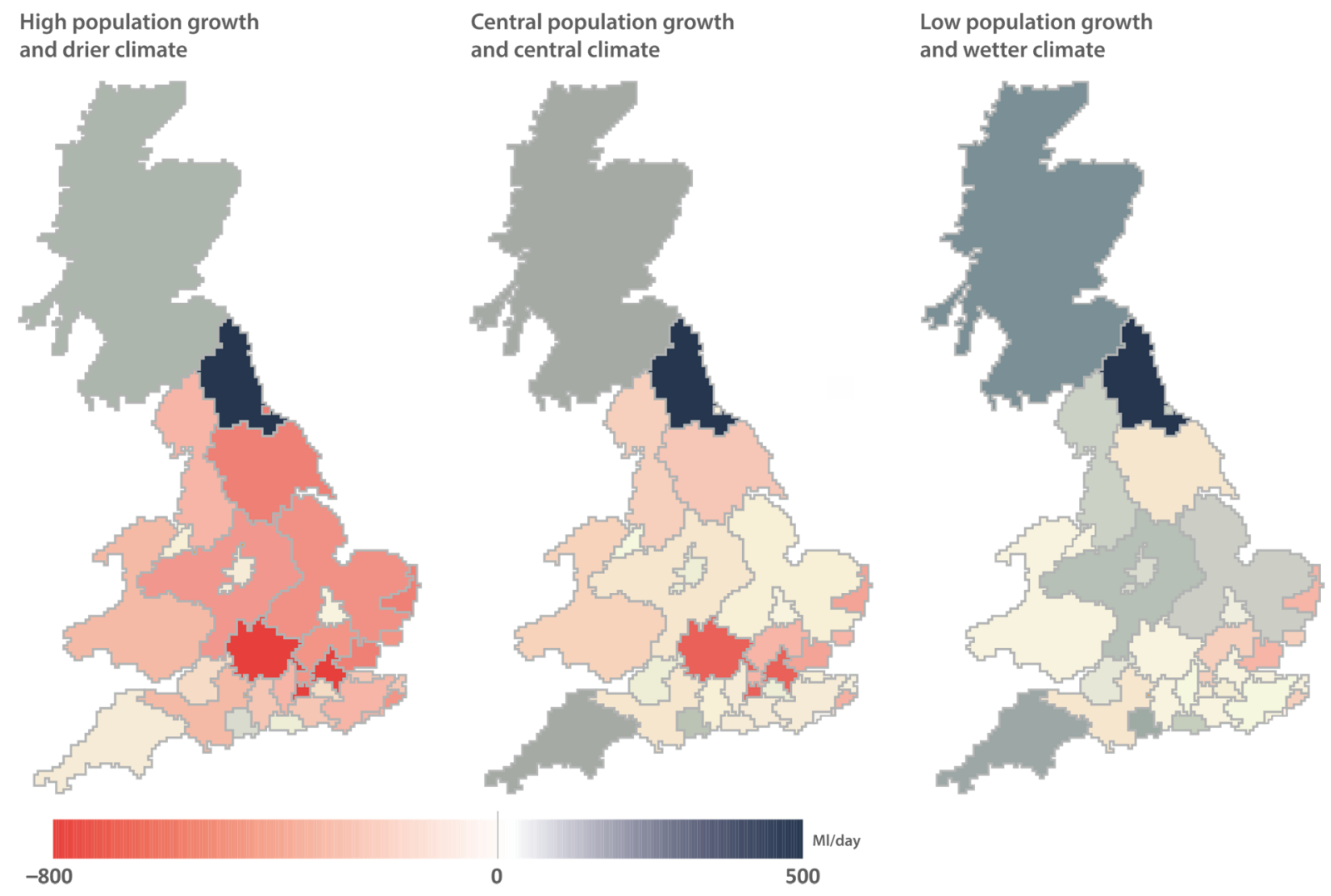

Figure 3: Simulated water balances for each water company in 2040 under the 'No Build' strategy and the three alternative socioeconomic and climatic scenarios.

Each of the five investment strategies examined here attempt to meet the water demands of each scenario given their particular constraints and investment decision rules. A comparison of the Minimum Intervention (MI) and System Efficiency (SE) strategies provides insights into the extent to which national demand management goals might be able to enhance the reliability of water supplies. These two strategies differ primarily in this regard:, Ml involves a $2 \%$ increase in domestic per capita consumption from 2015 to 2040 in contrast to the SE strategy, which involves on average a $20 \%$ (approx. $30 \mathrm{Ml} /$ person/day) decrease across all WRZs. The SE strategy experiences higher costs as a result of demand management efforts, but also enjoys reductions in water supplied (abstracted), as well as improved reliability and lower $\mathrm{CO}_{2} \mathrm{e}$ emissions. Nonetheless, widespread reduction in per capita consumption is not, on its own, able to prevent reliability issues in all WRZs in all climate and population scenarios.

The Capacity Expansion (CE) strategy, which involves no demand management and a subsequent $4 \%$ rise in average per capita consumption, requires heavy investments in traditional infrastructure options to meet the growing demand, including expansion of reservoir capacity, groundwater extraction, and water transfers between companies (as shown in Table 3). The CE strategy is able to achieve similar levels of reliability as the Ml strategy, but with far more water being abstracted, and higher emissions. However, despite having essentially no limits on the amount that can be spent on traditional infrastructure, the CE strategy is not able to guarantee security of supply.

The solution provided by the National Planning (NP) strategy incorporates all actions in the CE strategy while also allowing water companies that have surplus water, such as those that are part of Scottish Water and Dwr Cymru, to expand their capacity in order to supply water companies that run out of viable options. This strategy is able provide water security across 
the breadth of socio-economic and climatic scenarios with no water restrictions, but at a significantly higher cost compared to other strategies.

Table 3: A summary of the change in public water supplies gained from the various investments options used by each strategy up to 2040 under the central population and climate scenario (MI/day). Note that all models also involve increases in demand and leakage due to population increases which effectively reduces the amount of water gained by leakage and demand reduction efforts reported in this table

\begin{tabular}{|l|r|r|r|r|r|}
\hline & \multicolumn{1}{|c|}{ MI } & \multicolumn{1}{c|}{ CE } & \multicolumn{1}{c|}{ NP } & \multicolumn{1}{c|}{ SE } & \multicolumn{1}{c|}{ SR } \\
\hline Aquifer Recharge & 100 & 65 & 85 & 20 & 200 \\
\hline Desalination plant & 40 & 45 & 45 & 80 & 25 \\
\hline Effluent Re-use & - & - & - & - & 2,500 \\
\hline New Groundwater & 80 & 130 & 150 & 30 & 100 \\
\hline Reservoir & 6,500 & 7,200 & 18,500 & 2,500 & 3,900 \\
\hline Transfer & - & 670 & 7,800 & & 750 \\
\hline Leakage Reduction & 180 & 220 & 250 & 1,000 & 900 \\
\hline Demand Reduction & - & - & - & 1,100 & \\
\hline
\end{tabular}

The NP strategy and the System Restructure (SR) strategy are the only two strategies able to avoid Level 1 water restrictions in all scenarios. The NP strategy achieves this goal with no demand management (per capita consumption actually increases $4 \%$ by 2040), but with heavy investment in reservoirs and water transfers. The SR strategy achieves this goal with a combination of both moderate demand management (16\% decreases in per capita consumption by 2040) and investment in traditional and emerging investment options, such as aquifer recharge, effluent re-use and some investment in water transfers.

\section{Multi-criteria decision analysis}

The results of the MCDA analysis are presented in Figure 4 and 5, and show how each strategy performs across 240 runs of the sensitivity analysis under each of the three scenarios (Figure 4) and the three alternative preference sets (Figure 5). Using the ELECTRE III algorithm, each strategy is ranked from 1 to 6 in each run of the sensitivity analysis. The rank of 1 indicates the most preferred strategy. These rankings are then averaged across all of the runs for each scenario and performance set. The lower the average ranking, the better the strategy is considered to have performed according to the preference set.

The average ranking for each of the strategies was calculated as 4.4 for the No Build, 3.1 for Minimum Intervention, 2.8 for Capacity Expansion, 2.3 for National Planning, 1.4 for System Efficiency and 1.3 for System Restructure. As expected, the 'control' No Build (NB) strategy was the least preferred across all the scenarios and preference sets, providing some validation for the ranking process. The remaining results reveal the System Restructure (SR) and System Efficiency (SE) as the most preferred strategies. The SR is preferred overall, however, it is not the best ranked strategy across all preference sets and scenarios of uncertainty. SE is preferred in the neutral preference set (NoPref) and the Low and High scenarios. Despite having significantly higher costs, the SR strategy is clearly preferred to the SE strategy in terms of cost and security of supply. However, the SE strategy performs better based on environmental criteria by requiring less abstractions and producing lower emissions. 


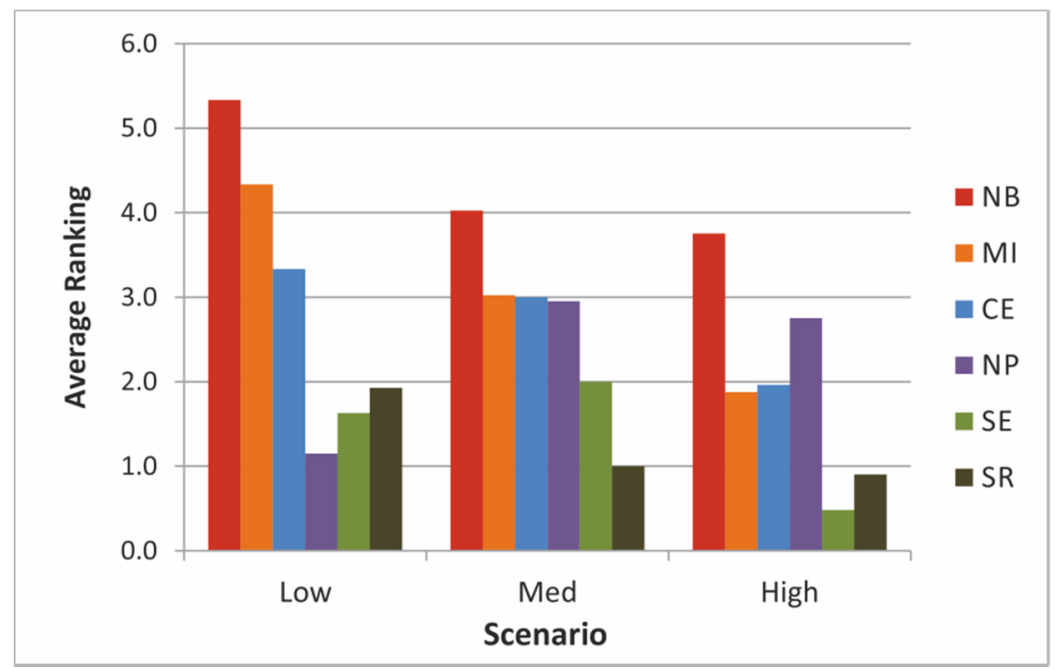

Figure 4: Results of the MCDA sensitivity analysis grouped by the three preference sets including the No Preference (NoPref), Green is Good (Green) and Security \& Cost (SecCost) sets. Lower rankings are preferred. Strategies shown are NB=No Build, MI=Minimum Intervention, CE=Capacity Expansion, NP=National Planning, SE=System Efficiency \& SR=System Restructure.

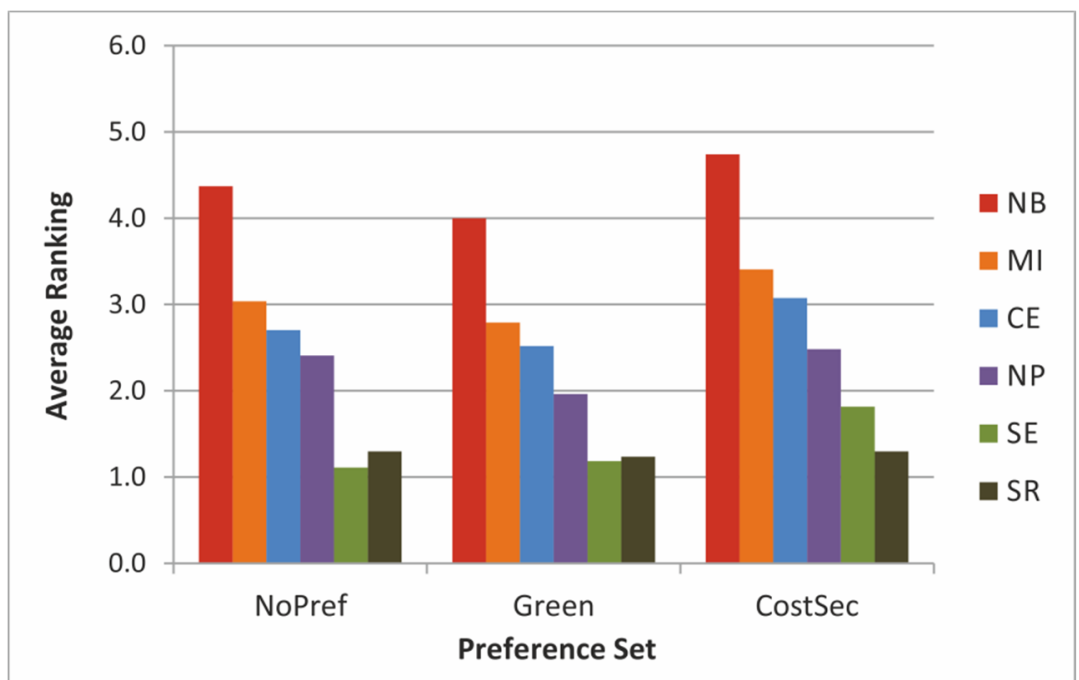

Figure 5: Results of the MCDA sensitivity analysis grouped by scenario including the Low and Wet (Low), Central (Med) and High and Dry (High) scenarios. Lower rankings are preferred. Strategies shown are NB=No Build, Ml=Minimum Intervention, CE=Capacity Expansion, NP=National Planning, SE=System Efficiency \& SR=System Restructure.

It should be noted that the uniform application of demand management and leakage reduction in each of these two preferred strategies (SR and SE), partially handicapped their modelled performance. In practice, these measures could be scaled up and down more flexibly across the various WRZs and hence could be applied less stringently in the Low and Wet scenarios, making them likely to be even more cost effective than how they are modelled here.

\section{Conclusions}

The increasing challenges of population growth, climate change and unsustainable use of natural water resources in Britain are prompting a more strategic approach to water resources planning. In this paper we have presented a national perspective on these challenges for Great Britain, innovatively framed in terms of meeting the "water trilemma" of achieving security of supply, affordability and environmental sustainability. 
The approach presented in this paper is based on a streamlined representation of the water supply-demand balance at a water resource zone level. The model incorporates water storage, demand and leakage management, inter-zonal transfers and geographically explicit estimates of changing water demand. The model inevitably simplifies the complex operation of water supply systems, but compares favourably with other similar studies and water company plans, confirming the projections are a reasonably realistic reflection of more accurate local studies. The advantage of this novel approach, however, is that it provides a consistent methodology for analysing water management strategies for all water companies, with any number of strategies available for examination across many different scenarios, strategies and stakeholder preference sets. Such a methodology can be applied in any region, country or context.

We have explored a range of contrasting strategic approaches to tease out the inevitable trade-offs between the three objectives of the water trilemma. Past policy decisions in the water industry suggest that Great Britain is currently being managed with a strong preference towards water security and affordability (Cashman, 2006, Pearce et al., 2013). In which case the results of this study would recommend an approach based around the principles of the System Restructure strategy with its open approach to innovative supply options, balanced with demand-side management. This approach, however, was not necessarily shown to be the most robust in terms of 'uncertainty,' which was represented by the wide-ranging socioeconomic and climatic scenarios explored. This suggests that, despite its emphasis on security of supply, such an approach might not actually be the most 'risk-averse' for all concerned.

Inter-company transfers can provide water security and are thus are being seen as an increasingly necessary consideration from a national perspective (Arkell and Piper, 2010). Here we modelled inter-company transfers as a solution in isolation from demand and leakage management, and in this context found that relying on inter-company transfers required a great deal more infrastructure in some scenarios. Relying on this approach may therefore risk cost overruns because infrastructure assets may be required in more places to accommodate supply shortfalls that may occur in different regions in the equally likely climate scenarios.

The results of this modelling effort promote demand management and leakage reduction as "trilemma-friendly" solutions, being robust, flexible in application, scalable, and relatively low carbon, whilst not involving further water withdrawals from the natural environment. However, such measures may not be sufficient in all WRZs, and such solutions may have their own inherent social risk in whether behavioural changes can be relied on as being longlasting. Which once again indicates the need for consideration of inter-zonal water transfers in the more challenging scenarios and locations.

This analysis therefore recommends a balanced approach, allowing for some inter-basin water transfers while also engaging local solutions, including water re-use, combined with scalable actions for demand management and leakage reduction. As in all such research involving modelling complex systems, more can always be done to improve the fidelity of this analysis. Nevertheless, by pulling apart the major trade-offs involved in securing affordable and sustainable water resources at a national scale, we have essentially provided a preliminary roadmap for navigating Great Britain's water trilemma. 


\section{Acknowledgments}

This research was funded by the U.K. Engineering and Physical Sciences Research Council (EPSRC) under Grant EP/101344X/1 and by the Natural Environment Research Council [Consortium on Risk in the Environment: Diagnostics, Integration, Benchmarking, Learning and Elicitation (CREDIBLE); grant number NE/J017450/1].

\section{References}

ARKELL, B. \& PIPER, B. 2010. Assessment of regulatory barriers and constraints to effective interconnectivity of water supplies. R\&D Technical Report WT0921/TR. DEFRA, Department for Environment Food and Rural Affairs.

ALMEIDA DIAS, J., FIGUEIRA, J. E. R. \& ROY, B. 2006. The software ELECTRE III-IV, methodology and user manual (version 3.x). Paris, France: University Paris-Dauphine Lamsade.

ARNELL, N. W. 2004. Climate-Change impacts on river flows in Britain: The UKCIP02 Scenarios. Water and Environment Journal, 18, 112-117.

BECK, M. \& VILLARROEL WALKER, R. 2013. Nexus security: governance, innovation and the resilient city. Frontiers of Environmental Science \& Engineering, 7, 640-657.

BORGOMEO, E., HALL, J. W., FUNG, F., WATTS, G., COLQUHOUN, K. \& LAMBERT, C. 2014. Risk-based water resources planning: Incorporating probabilistic nonstationary climate uncertainties. Water Resources Research, 50, 6850-6873.

BROWN, C. \& WILBY, R. L. 2012. An alternate approach to assessing climate risks. Eos, Transactions American Geophysical Union, 93, 401-402.

CASHMAN, A. 2006. Water regulation and sustainability 1997-2001: Adoption or adaptation? Geoforum, 37, 488-504.

DEFRA 2012. The UK Climate Change Risk Assessment 2012 Evidence Report. Accessed from http://randd.defra.gov.uk/Default.aspx?Menu=Menu\&Module=More\&Location=None\&Complet ed=0\&ProjectID=15747\#RelatedDocuments on 29/6/2016.

EA, OFWAT, DEFRA \& GOVERNMENT, W. 2012. Water Resources Planning Guidelines -The technical methods and instructions. Bristol: Environment Agency, The Water Services Regulation Authority, Department for Environment, Food and Rural Affairs, Welsh Government.

ENVIRONMENT AGENCY 2012. The case for change - current and future water availability. Bristol: Environment Agency.

ENVIRONMENT AGENCY, OFWAT, DEFRA \& WELSH GOVERNMENT 2012. Water Resources Planning Guideline.

GIULIANI, M., HERMAN, J. D., CASTELLETTI, A. \& REED, P. 2014. Many-objective reservoir policy identification and refinement to reduce policy inertia and myopia in water management. Water Resources Research, 50, 3355-3377.

HALL, J. W., TRAN, M., HICKFORD, A. J. \& NICHOLLS, R. J. 2016. The Future of National Infrastructure. A System-of-Systems Approach, Cambridge, Cambridge University Press.

HALL, J. W., WATTS, G., KEIL, M., DE VIAL, L., STREET, R., CONLAN, K., O'CONNELL, P. E., BEVEN, K. J. \& KILSBY, C. G. 2012. Towards risk-based water resources planning in England and Wales under a changing climate. Water and Environment Journal, 26, 118-129.

HANNAFORD, J. \& BUYS, G. 2012. Trends in seasonal river flow regimes in the UK. Journal of Hydrology, 475, 158-174.

HASSAN, J. 2013. Application of ELECTRE III and Shannon Entropy for Strategy Selection. International Journal of Innovation and Applied Studies, 4, 189-194.

HERMAN, J., REED, P., ZEFF, H., AND CHARACKLIS, G. 2015. How Should Robustness Be Defined for Water Systems Planning under Change? Journal of Water Resources Planning and Management, 0, 04015012.

HR WALLINGFORD 2015. CCRA2: Updated projections of water availability for the UK. Final Report. HR Wallingford.

HURFORD, A. P., HUSKOVA, I. \& HAROU, J. J. 2014. Using many-objective trade-off analysis to help dams promote economic development, protect the poor and enhance ecological health. Environmental Science \& Policy, 38, 72-86.

IVES, M. C. \& SIMPSON, J. M. 2017. Scenarios of future water availability in the UK. National Infrastructure Commission.

JENKINS, M., LUND, J., HOWITT, R., DRAPER, A., MSANGI, S., TANAKA, S., RITZEMA, R. \& MARQUES, G. 2004. Optimization of California's Water Supply System: Results and Insights. Journal of Water Resources Planning and Management, 130, 271-280. 
JENKINS, G. J., MURPHY, J. M., SEXTON, D. S., LOWE, J. A., JONES, P. D., and KILSBY, C. G.: UK Climate Projections: Briefing report, Met Office Hadley Centre, Exeter, UK, 2009

KASPRZYK, J. R., REED, P. M., KIRSCH, B. R. \& CHARACKLIS, G. W. 2009. Managing population and drought risks using many-objective water portfolio planning under uncertainty. Water Resources Research, 45, n/a-n/a.

LEMOS, D., DIAS, A. C., GABARRELL, X. \& ARROJA, L. 2013. Environmental assessment of an urban water system. Journal of Cleaner Production, 54, 157-165.

MCMAHON, T. A., ADELOYE, A. J. \& ZHOU, S.-L. 2006. Understanding performance measures of reservoirs. Journal of Hydrology, 324, 359-382.

PEARCE, R., DESSAI, S. \& BARR, S. 2013. Re-Framing Environmental Social Science Research for Sustainable Water Management in a Changing Climate. Water Resources Management, 27, 959-979.

POFF, N. L., BROWN, C. M., GRANTHAM, T. E., MATTHEWS, J. H., PALMER, M. A., SPENCE, C. M., WILBY, R. L., HAASNOOT, M., MENDOZA, G. F., DOMINIQUE, K. C. \& BAEZA, A. 2015. Sustainable water management under future uncertainty with eco-engineering decision scaling. Nature Clim. Change, advance online publication.

POST. 2017. Reform of Freshwater Abstraction, POSTnote 546, January 2017, Houses of Parliament, Accessed 1/12/2017 at https://researchbriefings.parliament.uk/ResearchBriefing/Summary/POST-PN-0546

PRUDHOMME, C., HAXTON, T., CROOKS, S., JACKSON, C., BARKWITH, A., WILLIAMSON, J., KELVIN, J., MACKAY, J., WANG, L., YOUNG, A. \& WATTS, G. 2013. Future Flows Hydrology: an ensemble of daily river flow and monthly groundwater levels for use for climate change impact assessment across Great Britain. Earth Syst. Sci. Data, 5, 101-107.

R CORE TEAM 2013. R: A Language and Environment for Statistical Computing. R Foundation for Statistical Computing. Vienna, Austria.

ROUGIER, J. 2007. Probabilistic Inference for Future Climate Using an Ensemble of Climate Model Evaluations. Climatic Change, 81, 247-264.

ROY, B. 1978. Electre III: Un algorithme de classements fonde sur une représentation floue des preferences en presence de critères multiples. Cahiers du Centre d'Études de Recherche Opérationnelle, 3.

TOOMS, S., TROW, S., WALKER, H. \& UNITED KINGDOM WATER INDUSTRY RESEARCH. 2011. Long term leakage goals, London, UK Water Industry Research Limited.

WATER UK 2016. Water Resources Long Term Planning Framework. Technical Report. Atkins; Mott MacDonald; Nera; HR Wallingford; Oxford University.

ZAVADSKAS, E. K. \& TURSKIS, Z. 2011. Multiple criteria decision making (MCDM) methods in economics: an overview. Technological and Economic Development of Economy, 17, 397427.

ZEFF, H. B., KASPRZYK, J. R., HERMAN, J. D., REED, P. M. \& CHARACKLIS, G. W. 2014. Navigating financial and supply reliability tradeoffs in regional drought management portfolios. Water Resources Research, 50, 4906-4923. 


\section{Supplementary Material}

\section{The Great Britain Water Infrastructure Model}

The water supply model used in this analysis is the Great Britain Water Infrastructure Model (GBWIM) which was developed by the authors as part of the National Infrastructure Systems Model Long-term planning tool (NISMOD-LP) (Simpson et al., 2016). GBWIM is a high level national water resources model based on existing regional water resource management arrangements in Britain. The model tracks the water balance, and availability of water for supply, at the scale of Water Resource Zones (WRZ), aggregating estimates of surface and groundwater availability in each WRZ, and simulates the effect of investment in storage, transfer, re-use and desalination supply infrastructure, as well as changes in water use and leakage.

\section{Supply Module: Baseline Water Supply Modelling}

In order to assess future resources from a supply/demand perspective in GBWIM, baseline water supply projections from the Future Flows Hydrology (FFH) dataset are converted into supply quantities available for future abstraction under a range of strategies for investment in water supply infrastructure. These supply quantities or 'yields' are defined as the deployable outputs, or long term maximum water available for abstraction, within each WRZ.

Where groundwater is used for all or part of an abstraction, the current groundwater deployable output is used in all current and future scenarios of available groundwater yields $\mathrm{Y}_{\mathrm{G}}$. River and reservoir sources are modelled in more detail.

For each WRZ a representative river gauge from the FFH set was identified. Modelled time series and sub-catchment areas were accessed from the National River Flow Archive ${ }^{2}$. Using recent WRMPs, information from water company drought plans, internet research and interviews with water company staff, a database of water supply assets was developed. For WRZ with multiple river abstraction points, a composite representative river abstraction subcatchment was created by summing the total non-nested abstraction sub-catchment areas, such that:

$$
A\left(r_{I}\right)=A\left(\bigcup_{i \in I} G(i)\right)
$$

where $A(r)$ is the sub-catchment area of composite river abstraction $r$, based on the set of river abstractions $I$, with $G(i)$ being the geometry of the sub-catchment of river abstraction $i$. The ratio of this to the sub-catchment modelled in the Future Flows dataset was used as a multiplier for the modelled Future Flows time series,

$$
Q\left(r_{I}\right)=\frac{A\left(r_{I}\right)}{A(o)} \times Q(o)
$$

\footnotetext{
${ }^{2}$ http://www.ceh.ac.uk/data/nrfa/
} 
in which $Q\left(r_{I}\right)$ is the flow time series for the composite river set $r_{I}$, and $A(o)$ is the area of the sub-catchment for the representative modelled Future Flow time series $Q(o)$.

If a WRZ features river intakes or reservoir storage the total catchment sizes for each of these are also derived from a Digital Elevation Model (DEM) and flows are extrapolated on the basis of the ratio of catchment sizes to identify future scenarios of total flow passing river intakes and total flow available to reservoirs.

Reservoir sub-catchments were derived using a digital terrain model acquired from EDINA Digimap $\mathrm{DEM}^{3}$ at $50 \mathrm{~m}$ horizontal resolution. Similar to the development of a representative abstraction for each WRZ, a representative reservoir was identified using the total reservoir capacity, such that:

$$
C\left(R_{J}\right)=\sum_{j \in J} C(j)
$$

where $C\left(R_{J}\right)$ is the storage of the composite reservoir $R_{J}$ which represents the set of all reservoirs in the $W R Z J$, and the sum of the non-nested reservoir sub-catchment areas,

$$
A\left(R_{J}\right)=A\left(\bigcup_{j \in J} G(j)\right)
$$

giving the flow time series for a composite reservoir as:

$$
Q\left(R_{J}\right)=\frac{A\left(R_{J}\right)}{A(o)} \times Q(o)
$$

with sub-catchments again using information on modelled flows under climate change to represent reservoir inflows. Where reservoirs are offline, reservoir intake sub-catchment areas are included in the total of WRZ reservoir sub-catchment areas.

Acceptable return periods of future shortage are identified from the drought plan for each WRZ outlined in the WRMP, which is then used to identify the maximum yield from each WRZ which will not violate these rules. During shortages, per capita demand is assumed to be reduced by a percentage based on estimates in WRMPs, allowing us to calculate the maximum amount of deployable output that can be abstracted without incurring a breach of

${ }^{3}$ http://digimap.edina.ac.uk/ 
level 1, level of service restrictions (which equates to around a 1 in 10 year drought). River abstraction yields are thus determined with consideration given to licenced minimum residual flows and maximum abstractions. The initial value for river yield $Y_{r}$ is set as:

$$
Y_{r}=P\left(Q_{r}-m_{r}, l_{r}\right)
$$

in which $m_{r}$ is the minimum residual flow and $l_{r}$ is the licenced maximum abstraction for river $r . P$ is a function relating to the desired return period of the yield. This is used in a similar capacity to 'dry year' terms in water planning, except in this case the return period of the dry condition is set in line with the return period of the minimum acceptable period $p$ set out in the water company drought plan for the shortest return period drought event. Here, $P(Q)$ is based on the series of annual minima $\left(q_{1}, q_{2}, q_{3}, \ldots, q_{n}\right)$ of the time series $Q ; P(Q)$ is the $\frac{n}{p}$ th smallest value of this series.

A similar equation is used to identify licenced reservoir input abstractions, which can be represented as

$$
Q_{i n, R}=\min \left(Q_{R}-m_{R}, l_{R}\right)
$$

Here, $Q_{i n, R}$ is used as a vector input to the reservoir storage. Due to the filtering effect of reservoir storage, reservoir yields are calculated using an iterative numerical approach. Stored water $S$ in the composite reservoir at time $t$ is calculated as

$$
S_{t}= \begin{cases}C_{R}, & \text { if } S_{t-1}+Q_{i n, R}-Y_{R}>C_{R} \\ 0, & \text { if } S_{t-1}+Q_{i n, R}-Y_{R}<0 \\ S_{t-1}+Q_{i n, R}-Y_{R}, & \text { otherwise }\end{cases}
$$

At the first time step $(t=1)$ the reservoir storage is set to equal to the current reservoir capacity as a starting point. The yield for the composite reservoir, $Y_{R}$, is then identified iteratively as presented in Figure A1. 


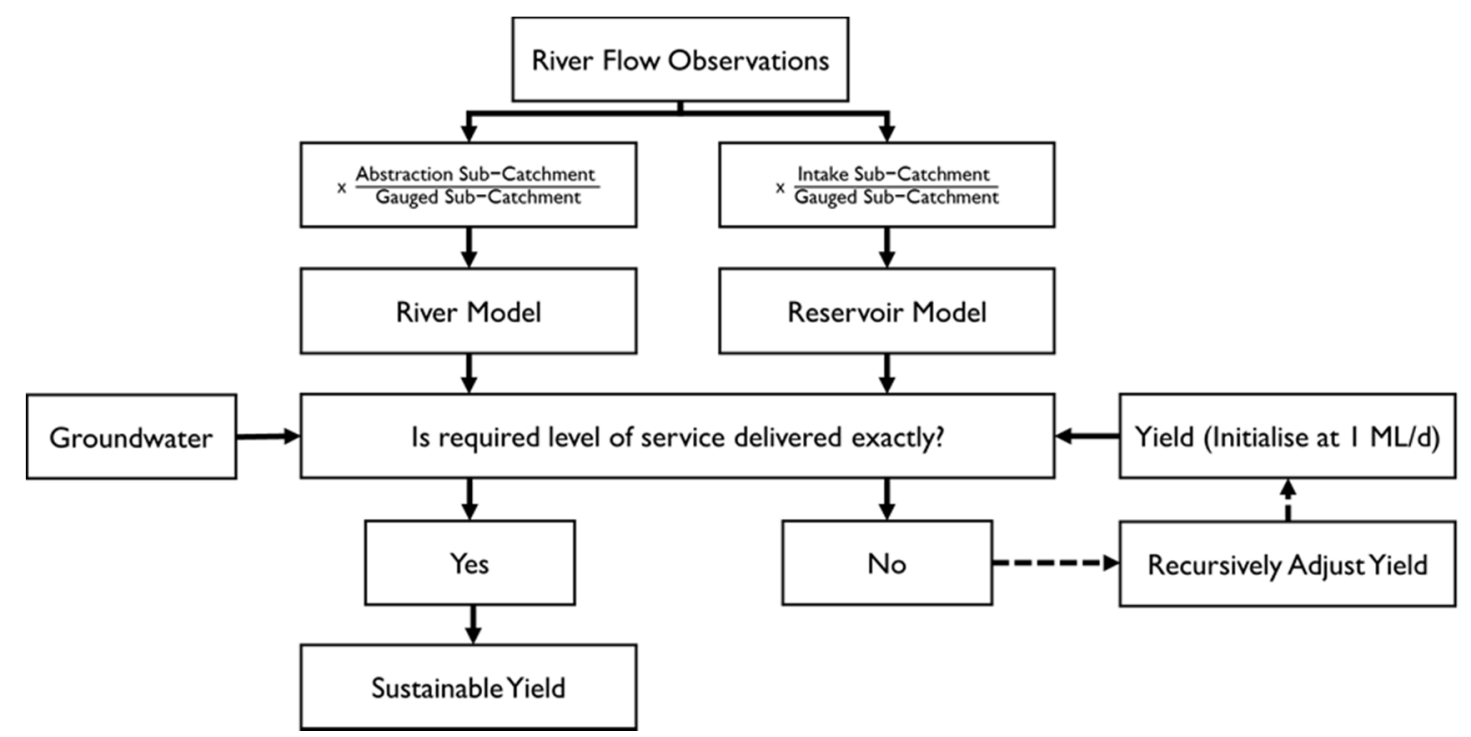

Figure A1: A stylised representation of the logic used to convert the river flows from the 11 Future Flow climate scenario data sets to sustainable yields for each WRZ

The use of catchment size as a proxy for proportional hydrological conditions is a further assumption required for the parsimony of the model. To mitigate this, catchments of approximately similar size were identified wherever possible, with spatial proximity also taken into consideration. Amalgamating rivers intakes and reservoirs to lumped models relies on the assumption that they operate in a similar manner to the individual intakes and reservoirs. This simplification is mitigated by also introducing amalgamated licence conditions that better approximate specific local requirements. It is assumed that no reservoir management rules are implemented, which is justified as the majority of reservoirs are principally used for water storage.

Values for monthly minimum acceptable storages are identified for the composite reservoir from those given for the largest reservoir in the WRZ of the water company's drought plan. These are scaled proportionally to the capacity of the composite reservoir. In line with the drought plans, the water system can be considered to have failed if these minima are exceeded on average more regularly than the return period. Violations of these thresholds are considered on an annual basis, so more than one violation per year is considered a single violation in that year. The maximum acceptable value for $Y_{R}$ is identified as the maximum value of $Y_{R}$ which does not fail this criterion. As the relationship between $Y_{R}$ and $S$ is monotonic, $Y_{R}$ is increased from 1 megalitre per day (MLD) by 1 MLD per iteration until failure is observed.

Total possible yield from a WRZ is then identified as

$$
Y=Y_{G}+Y_{r}+Y_{R}+Y_{m i s c}
$$


where $Y_{\text {misc }}$ represents alternative sources such as desalination and spring supplies currently in use.

Where a transfer of water between WRZ exists, this is modelled as a steady-state exchange between two WRZ and is counted as additional supply in the receiving zone and reduced supply in the donor zone.

A simple form of transient yield under climate change is provided by dividing Future Flows Hydrology series into three sections (1951-2014, 2015-2049 and 2050-2098), using these to identify available water for the central year in each case and interpolating linearly between these points, as set out by Prudhomme et al. (2012a). Thus, for each WRZ, eleven time series of available supply, indicative of plausible climate change futures, are identified at each annual time step of the model run. The hydrology and water supply module receives information on river flows within the WRZ from the Future Flows Hydrology dataset and provides 11 scenarios of river flows from 1960 to 2100 at a single point within the WRZ. The additional 11 low and 11 high emission scenarios are produced using the method but applied to the alternative low and high FFH datasets supplied by the CCRA2 project.

\section{Calibration}

Several factors with potential to influence the modelled frequency of system failure were not included in the model due to data unavailability. Specifically, treated water storage capacities are not known and can significantly influence system vulnerability. In order to represent this ability to reduce the influence of short term shortfall, a moving average filter was applied to observations of flow time series such that

$$
g(t, p)=\frac{\sum_{n=0}^{p-1} Q(t-n)}{p}
$$

where $Q(t)$ is the observation of flow at time $t, p$ is the calibrated parameter of window size and $n$ indexes the time steps used in the moving average window. $p$ was iteratively calibrated 10,000 times per WRZ using the bisection method (Chapra and Canale, 2010), applying an absolute error objective function to minimise error in modelled return period of Level 1 events as compared to historic frequency of Level 1 events.

\section{Options Module: Calculation of costs of water supply options}

For each alternative investment type a linear regression was fitted to costs $v$ against additional water provided $\chi$ using the nonparametric Kendall-Theil method (Helsel and Hirsch, 2002). For a given operational lifetime $Y$ the total costs for implementing a new option of investment type I which provides a quantity of water $\chi$ can be represented as:

$$
\begin{gathered}
\operatorname{TotEx}_{I}=\operatorname{CapEx}_{I}+\sum_{y=1}^{\mathrm{Y}} \frac{v O p E x_{I}}{(1+r)^{\mathrm{Y}}} \\
\operatorname{CapEx}_{I}=\alpha_{I, \gamma}+\beta_{I, \gamma} \chi
\end{gathered}
$$




$$
O p E x_{I}=\Delta_{y}\left(\alpha_{I, \omega}+\beta_{I, \omega} \chi\right)
$$

where $y$ is years, $r$ is the discount rate (set at $5 \%$ ), and $\alpha_{I, \gamma}, \beta_{I, \gamma}$ and $\alpha_{I, \omega}, \beta_{I, \omega}$ are the intercept and slope regression coefficients for capital and operating expenditure respectively. Two options were costed using variants of this model. Reservoir expansions (RE) were modelled as:

$$
\begin{aligned}
& \operatorname{CapEx}_{R E}=\alpha_{R E, \gamma}+\beta_{R E, \gamma} \Delta_{C} \\
& O p E x_{R E}=\alpha_{R E, \omega}+\beta_{R E, \omega} \Delta_{C}
\end{aligned}
$$

Water transfers (TR) were modelled as:

$$
\begin{gathered}
\operatorname{CapEx}_{T R}=\alpha_{T R, \gamma}+\beta_{T R, \gamma} \chi+\Gamma_{T R, \gamma} \delta \\
O p E x_{T R}=\Delta_{y}\left(\alpha_{T R, \omega}+\beta_{T R, \omega} \chi+\Gamma_{T R, \omega} \delta\right)
\end{gathered}
$$

where $\Gamma$ is a further regression parameter relating the distance water is transferred to CapEx and OpEx costs, and $\delta$ quantifies that distance $(\mathrm{km})$. Values used for these parameters for each of the asset options are given in Table A1.

Table A1: A list of parameters used to produce Capex and Opex estimates for each asset type by asset capacity ('000£/MI). Energy use for each asset type is used to calculate emissions (kWh/MI)

\begin{tabular}{|l|c|c|c|c|c|}
\hline Asset Option & $\begin{array}{c}\text { Capex } \\
\text { Intercept }\end{array}$ & $\begin{array}{c}\text { Capex } \\
\text { slope } \\
\beta_{I, \gamma}\end{array}$ & $\begin{array}{c}\text { Opex } \\
\text { Intercept }\end{array}$ & $\begin{array}{c}\text { Opex } \\
\text { slope }\end{array}$ & $\begin{array}{c}\text { Energy use } \\
\text { (kWh/MI) }\end{array}$ \\
\hline Reservoir & 21,433 & 1.3 & 1,807 & 0.007 & 258 \\
\hline Desalination plant & 12,981 & 2,959 & 1,015 & 527 & 5690 \\
\hline Transfers & 500 & 50 & 300 & 30 & 365 \\
\hline Leakage Reduction & 13,563 & 473 & 1,401 & 405 & 50 \\
\hline Aquifer Recharges & 12,981 & 79 & 1,015 & 527 & 294 \\
\hline Demand Reductions & 10 & 4,726 & 5 & 1,854 & 50 \\
\hline Effluent Re-uses & 24,180 & 5,013 & 8,912 & 694 & 1161 \\
\hline New Ground water & 12,981 & 79 & 1,015 & 527 & 294 \\
\hline
\end{tabular}

In determining the next investment option for each water company an optimal planning decision algorithm minimises the Total Present Value Costs per unit of water supplied for an investment $I($ TotPVC $I)$ across the suite of available investment options: 


$$
\operatorname{Min}\left(\operatorname{TotPVC}_{I}=\operatorname{CapEx}_{I}+\sum_{t} \frac{o p E x_{I, y}}{(1+d)^{y}}\right)
$$

where CapEx $\mathrm{I}_{\mathrm{I}}$ represents the capital expenditure for the investment I, assumed to be paid in the year that the option is implemented; $0 \mathrm{pEx}_{\mathrm{I}, \mathrm{t}}$ represents the operating expenditure for the investment I in year $y$; and $d$ is the discount rate, which is taken as $5 \%$.

Once the minimum cost investment is found, the intervention is implemented immediately and the additional yield generated is added to supply within the company from year $y+1$ onwards. Each implemented option is recorded by year and quantity of water provided/saved.

A number of simplifying assumptions were used to make the options module more tractable. Firstly, the options module assumes that linear extrapolation of existing water resource infrastructure costs can provide representative costs of future infrastructure. This may be unsound if the relationships are non-linear (AECOM, 2015), if there are significant local factors which influence cost (e.g. it will be more expensive to reduce per capita demand in areas are already lower than the average), if future technologies alter these costs, or if the cost estimates given by water companies do not include all construction and maintenance costs. Secondly, operating costs are based on the maximum capacity of any asset investments (which might over-estimate costs of options such as desalination plants).

Initial estimates of per capita demand, deployable output and leakage

Initial estimates used in the modelling for 2015 per capita demand, deployable output and total distribution leakage for each company are provided below in Table A2. 
Table A2: Model values for 2015 average per capita demand (PCD), distribution leakage (Leakage) and Deployable Output (DO) for each of the water companies in Britain (see Figure 1) as extracted from each company's WRMPs

\begin{tabular}{|l|r|r|r|}
\hline Company & PCD $(\mathrm{l} / \mathrm{c} / \mathrm{d})$ & Leakage $(\mathrm{Ml} / \mathrm{d})$ & $\mathrm{DO}(\mathrm{Ml} / \mathrm{d})$ \\
\hline Affinity & 154 & 196 & 920 \\
\hline Albion & 149 & 3 & - \\
\hline Anglian & 136 & 191 & 1,565 \\
\hline Bristol & 163 & 43 & 464 \\
\hline Cambridge & 141 & 14 & 113 \\
\hline Cholderton and Distr & 145 & 0 & 1 \\
\hline Dee Valley & 146 & 10 & 90 \\
\hline Essex and Suffolk & 160 & 12 & 387 \\
\hline Northumbria & 141 & 137 & 998 \\
\hline Portsmouth & 157 & 30 & 310 \\
\hline Scottish & 150 & 540 & 3,548 \\
\hline Bournemouth & 140 & 16 & 454 \\
\hline Severn & 130 & 468 & 1,963 \\
\hline South East & 173 & 95 & 766 \\
\hline South Staffordshire & 137 & 55 & 432 \\
\hline South West Water & 141 & 84 & 826 \\
\hline Southern & 145 & 15 & 763 \\
\hline Sutton and East Surr & 183 & 25 & 204 \\
\hline Thames & 153 & 659 & 3,070 \\
\hline United & 143 & 457 & 2,256 \\
\hline Welsh Water & 157 & 185 & 1,578 \\
\hline Wessex & 192 & 468 \\
\hline Yorkshire & 148 & 1,460 \\
\hline & & & \\
\hline
\end{tabular}




\section{Sustainability Changes}

Table A4: A list of Sustainability changes aggregated by Water Company including the year the reductions commence and their quantity in MI/year. Information extracted from the WRMP for each company and replicate those used in Water UK's "base" scenario which uses the confirmed/likely sustainability reductions defined in Water Resource Management Plans 2014 and includes $25 \%$ of the "unknown" impacts.

\begin{tabular}{|l|l|r|}
\hline Company & $\begin{array}{l}\text { Start } \\
\text { Year }\end{array}$ & $\begin{array}{l}\text { Reduction } \\
\text { (ML/year) }\end{array}$ \\
\hline Affinity Water & 2025 & 54,139 \\
\hline Anglian Water & 2020 & 51,812 \\
\hline Bristol Water & 2015 & 4,416 \\
\hline Cambridge & 2020 & 4,715 \\
\hline Essex \& Suffolk & 2020 & 547 \\
\hline Northumbrian & 2020 & 1,018 \\
\hline Portsmouth Water & 2020 & 2,190 \\
\hline Severn Trent Water & 2025 & 72,704 \\
\hline South East Water & 2020 & 12,280 \\
\hline South Staffordshire & 2020 & 6,205 \\
\hline South West Water & 2020 & 2,540 \\
\hline Southern Water & 2020 & 65,286 \\
\hline Thames Water & 2020 & 47,545 \\
\hline United Utilities & 2020 & 15,513 \\
\hline Wessex Water & 2020 & 8,107 \\
\hline Yorkshire Water & 2020 & 4,701 \\
\hline
\end{tabular}

\section{ELECTRE III Weightings}

Table A5: Central weighting and threshold values for the ELECTRE III MCDA analysis with the indifference threshold parameter (q), the preference thresholds (p) and veto thresholds (v). Note that a veto threshold was not applied to the CO2e emissions. The sensitivity analysis involved a $50 \%$ increase and decrease in each of these parameter values.

\begin{tabular}{|l|c|c|c|}
\hline & $\begin{array}{c}\text { Indifference } \\
(\mathrm{q})\end{array}$ & $\begin{array}{c}\text { Preference } \\
(\mathrm{p})\end{array}$ & $\begin{array}{c}\text { Veto } \\
(\mathrm{v})\end{array}$ \\
\hline 2040 Water Supplied & 10 & 15 & 25 \\
\hline 2040 Reliability & 5 & 15 & 30 \\
\hline 2040 Cumulative Cost & 15 & 25 & 45 \\
\hline 2040 Cumulative CO2e Emissions & 10 & 30 & 50 \\
\hline
\end{tabular}

